\title{
MAGNETORHEOLOGICAL (MR) FLUID AND ITS APPLICATIONS
}

\author{
Shigeru SHUTTO* and James R. TOSCANO** \\ * Lord Far East Inc. Japan Branch \\ 8-11-1 Nishi-Shinjuku, Shinjuku-ku, Tokyo, 160-0023 Japan \\ (E-mail: s-shutto@lfe.cojp) \\ ** Materials Business Unit, Lord Corporation \\ 406 Gregson Drive, Cary, NC 27512-8012 USA \\ (E-mail: Jim_Toscano@lord.com)
}

\begin{abstract}
Magnetorheological (MR) fluid is a functional, smart or controllable fluid, which responds to magnetic field, changing its rheological properties. The increased resistance to flow of an MR fluid is proportional to the strength of magnetic field. A typical MR fluid consists of iron particles, suspended in a carrier liquid such as synthetic oil or water. Proprietary additives, to discourage gravitational settling and promote particle suspension, are added to enhance lubricity, modify viscosity, and inhibit wear. In recent years devices and systems using MR fluid technology have been commercialized across wide industry applications, including automotive, industrial and civil engineering. In that development two key issues for the commercial success of MR fluid technology - durability and settling - have shown continual improvement as a result of formulation research. As a result, MR fluids today are strong, durable, adaptable and highly developed with fundamental material data and device design and models.
\end{abstract}

\section{KEY WORDS}

Key words, Magnetorheological, Smart Fluid, Functional Fluid, Automotive, Commercial

\section{INTRODUCTION}

Since the first patent was issued to inventor Jacob Rabinow in the 1940s, magnetorheological (MR) fluids have remained mostly a laboratory curiosity with little practical use. In the late 1980s and 1990s, however, researchers began to get serious about developing the commercial viability of MR fluids, especially when other technologies began to converge that made practical use a real possibility. Microprocessors, sensor technologies and increasing electronic content and processing speeds have created control possibilities that didn't exist in Rabinow's time. Battery technology, fueled by the advance of the burgeoning cell phone industry, as well as new rare earth magnets now provide power in smaller packages than ever possible before.

Lord Corporation, after committing more than a decade of intense R\&D, holds the world's most extensive patent portfolio on MR fluid formulations, devices and systems. The company has developed additives, lubricants and suspension aids to keep iron particles in place while preventing them from grinding away at seals, gaskets and metal components. The company also has compiled a body of scientific data through aggressive life cycle testing and installed commercial applications that clearly demonstrate the effectiveness, durability and performance of MR fluids, devices and systems. 


\section{DESCRIPTION OF MR FLUID TECHNOLOGY}

MR fluids are materials that respond to a magnetic field with a dramatic change in rheological behavior. These fluids can reversibly change instantaneously from a freeflowing liquid to a semi-solid with controllable yield strength when exposed to a magnetic field. In the absence of an applied field, MR fluids are reasonably well approximated as Newtonian liquids when magnetic field is not given. For most engineering applications a simple Bingham plastic model is effective in describing the essential, field-dependent fluid characteristics, as shown in the model in Fig. 1.

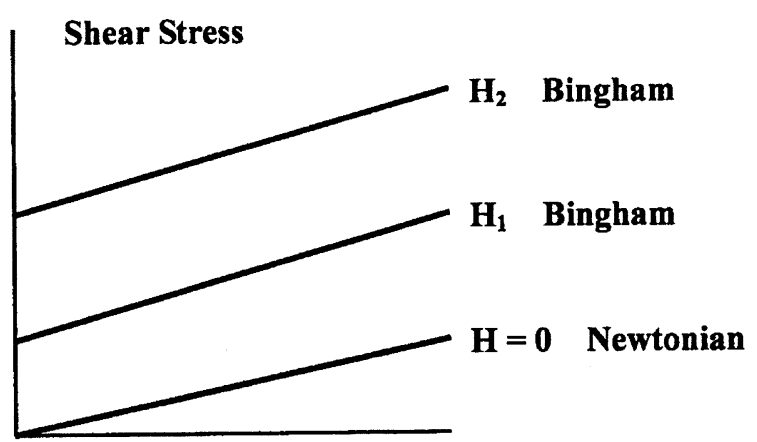

Shear Rate

Figure 1 Stress-Strain model of Newtonian and Bingham fluids

A typical MR fluid consists of $20-40$ percent by volume of relatively pure, 3-10 micron diameter iron particles, suspended in a carrier liquid such as mineral oil, synthetic oil, water or silicone oil. A variety of proprietary additives, similar to those found in commercial lubricants to discourage gravitational settling and promote particle suspension, are commonly added to Lord's state-of-the-art MR fluids to enhance lubricity, modify viscosity, and inhibit wear.

MR fluids made from iron particles exhibit maximum yield strengths of 50-100 $\mathrm{kPa}$ for applied magnetic fields of $150-250 \mathrm{kA} / \mathrm{m}$. MR fluids are not highly sensitive to moisture or other contaminants that might be encountered during manufacture and usage. Further, because the magnetic polarization mechanism is unaffected by temperature, the performance of MR-based devices is relatively insensitive to temperature over a broad temperature range (including the range for automotive use).

MR fluids contrast with electrorheological (ER) fluids, which are often referred to as smart or functional fluids, in various performances and properties as in Table 1.

\begin{tabular}{|c|c|c|c|}
\hline & & MR & ER \\
\hline \multirow[t]{3}{*}{$\Rightarrow$} & $\begin{array}{l}\text { Max. Yield } \\
\text { Stress }\end{array}$ & $50-100 \mathrm{kPa}$ & $2-5 \mathrm{kPa}$ \\
\hline & Max. Fleld & $\begin{array}{l}\sim 250 \mathrm{kA} / \mathrm{m} \\
\text { (limited by } \\
\text { saturation) }\end{array}$ & $\begin{array}{l}\text { } 4 \mathrm{kV} / \mathrm{mm} \\
\text { (llmited by } \\
\text { breakdown) }\end{array}$ \\
\hline & Vscosity & $0.1-1.0 \mathrm{~Pa}-\mathrm{s}$ & 0.1-1.0 Pa-s \\
\hline$\Rightarrow$ & $\begin{array}{l}\text { Operable } \\
\text { Temp. Range }\end{array}$ & $\begin{array}{l}-40 \text { to } 150^{\circ} \mathrm{C} \\
\text { (limited by carrier } \\
\text { fluld) }\end{array}$ & $\begin{array}{l}+10 \text { to }+90^{\circ} \mathrm{C} \text { (ionic, } \\
\text { DC) } \\
-25 \text { to }+125^{\circ} \mathrm{C} \\
\text { (non-ionic, } \mathrm{AC} \text { ) }\end{array}$ \\
\hline \multirow[t]{3}{*}{$\Rightarrow$} & Stablilty & $\begin{array}{l}\text { Unaffected by most } \\
\text { impurities }\end{array}$ & $\begin{array}{l}\text { Cannot tolerate } \\
\text { impurttles }\end{array}$ \\
\hline & $\begin{array}{l}\text { Response } \\
\text { Time }\end{array}$ & Milliseconds & Milliseconds \\
\hline & Density & $3.4 \mathrm{~g}^{1 \mathrm{~cm}^{3}}$ & $1.2 \mathrm{~g} / \mathrm{cm}^{3}$ \\
\hline$\Rightarrow$ & $\begin{array}{l}\text { Power } \\
\text { Supply } \\
\text { (typlcal) }\end{array}$ & $\begin{array}{l}2-25 V @ 1-2 A \\
(2-50 \text { watts) }\end{array}$ & $\begin{array}{l}2-5 \mathrm{kV} @ 1-10 \mathrm{~mA} \\
(2-50 \text { watts) }\end{array}$ \\
\hline
\end{tabular}

Table 1 Performance and properties of MR fluid and ER fluid

Most devices use MR fluids in a valve mode or directshear mode. Examples of valve mode devices include dampers and shock absorbers. Examples of direct-shear mode devices include clutches, brakes, and variable friction dampers.

\section{DAMPING SYSTEM APPLICATIONS}

\section{Automotive Seat Suspension}

MR fluid dampers had been used in seat suspensions for Class 8 trucks since 1998. The MotionMaster ${ }^{\mathrm{TM}}$ Ride Management System has proven capability to reduce topping and bottoming. Topping can lead to loss of control of the vehicle and bottoming can injure drivers. Seat vibration is monitored by the sensor, which sends signals to controller which controls electric currency to be given to the damper, which changes stiffness responding to vibration in 10 milliseconds.

Unlike standard air suspended seats the seating equipped with MotionMaster Ride Management system automatically adapts to both the driver's body weight and continually changing levels of shock and road vibration, improving driver responsiveness and control while reducing fatigue and risk of injury, Today $10,000+$ buses, trucks and off-highway vehicles are equipped with the System. [1] - [4]

\section{Cable-stay Bridges Stay Still}

Stay cables are prone to vibration due to wind and rain effects. Smart dampers have the potential efficiency several times that of standard oil dampers. Lord's MR dampers were employed at the Dongting Lake Bridge, Hunan Province, China in 2003. 


\section{Automotive Primary Suspensions}

Year 2002 marked the first broad-based automotive application for MR fluid technology. Delphi Automotive Systems, the world's largest automotive industry supplier, has since developed and commercialized the MagneRide $^{\mathrm{TM}}$ shock and strut system for a number of GM model cars and two future European vehicles slated for 2006. [5][6]

The Delphi mono-tube design employs an electromagnetic coil wrapped around the passageway between two chambers filled with custom formulated MR fluid from Lord Corporation. When the piston moves within the damper body, MR fluid flows between these two chambers and through the coil. Varying current in the coil controls the magnetic field in the coil, adjusting the yield stress or resistance-to-flow of the fluid, proportionally to the field, up to 1,000 times a second. The design has no electromechanical valves or small moving parts. The iron particles in the MR fluid form a dense network of chains when a magnetic field is applied to them, increasing the damping in the shock. When the magnetic field is removed, particles revert to their free, unchained form, allowing freer movement of the damper and thus lower damping.

All four corners of the vehicle are independently controlled by the MagneRide system with the fluid (and thus damping force) in the four damper/struts changing in response to vehicle speed and sensed road and driving conditions such as pot holes and lateral forces in high-speed turns. The faster response time (less than 10 milliseconds) of MR dampers, compared to other semi-active shocks, enables the suspension system to adapt to changing road conditions and dampen sudden impacts when driving over rough terrain.

MagneRide shocks have fewer moving parts than conventional controllable shocks - 60 percent fewer parts than Delphi's conventional semi-active damper system. The MagneRide system also requires very little power. Peak power is 20 watts at each of the system's four dampers. MR dampers are also quieter in operation and simpler to assemble.

The MagneRide system was extensively tested for performance and durability under strenuous environmental conditions prior to launch in 2002 on the Cadillac Seville STS and Chevrolet Corvette. Today, the MagneRide system is additionally in production on the Cadillac SRX and XLR, will be on the Buick Lucerne 2006 model and will soon launch on two European vehicles.

\section{MR SYSTEM DEVELOPMENT AND OPTIMIZATION}

The rheological properties of MR fluids depend on the concentration, size, distribution and shape of the iron particles, the carrier oil properties, additives, applied field, temperature and other variables. The interdependency of all of these factors is very complex and important to understand in optimizing the performance of these fluids within an MR device and control system for a particular application, as trade-offs must constantly be made in the design process.

Two areas of performance that received particular attention during Lord's decade-long MR development program in the 1990 s were settling stability and durability (wear and seal life) as MR fluids, when first invented, were not stable to long-term settling and could be quite abrasive in use.

As with any micron scale particulate suspension in which a density mismatch exists between the particle and fluid, long-term settling must be controlled. The specific application dictates to what extent and how the settling will be controlled. For example, an MR damper used to control seismic forces in a building has very demanding settling requirements, requiring limited variation in iron concentration within the fluid for years with no agitation. To achieve this level of stability, the off-state of the fluid must be allowed to rise and the system effect is compensated in the design of the MR valve in the damper. Conversely, an automotive shock is unlikely to remain static for multiple years and low off-state damping is necessary to provide a large control range (from off to full on).

Settling behavior of suspensions is typically characterized in two ways: clear layer formation and ease of re-dispersion of the settled suspension. The paint industry has spent decades developing correlations for accelerating settling and predictability in settling behavior. One rarely buys a can of paint and finds that the solids in the bottom, which are more dense than the fluid, cannot be easily re-dispersed with a paint stirrer.

Similarly Lord has developed accelerated settling tests and developed correlations with real-time settling behavior. From these tests, we have been able to develop specifications for clear layer formation and redispersibility to satisfy the requirements of damper applications including automotive shocks. We know from our testing that as long as the clear layer in an MR fluid is less than 30010, the fluid in an MR automotive shock will re-disperse. In actual real-time and accelerated testing, Lord MR fluids do not exceed $20 \%$ clear layer in over 200 days of settling. 
Delphi has tested MR shocks with the same accelerated settling tests that Lord uses for testing the base MR fluid. Shocks were stored horizontally or vertically and thermally cycled for multiple days to simulate settling for periods up to the equivalent of one year. At the end of the settling time, the shocks were carefully loaded into a test frame and the forces from the very first cycle of use were recorded. Figure 2 shows the results for a simulated test time of one year. While the first cycle shows an initial increase in force, by the second cycle, the damper produces forces identical with the original performance of the shock. Thus it takes only one stroke of the damper to completely re-disperse the MR fluid, even after 1 year of settling. Current MR fluid data from Lord indicates that our MR fluid formulation will continue to be re-dispersible, even after 10 years of storage .

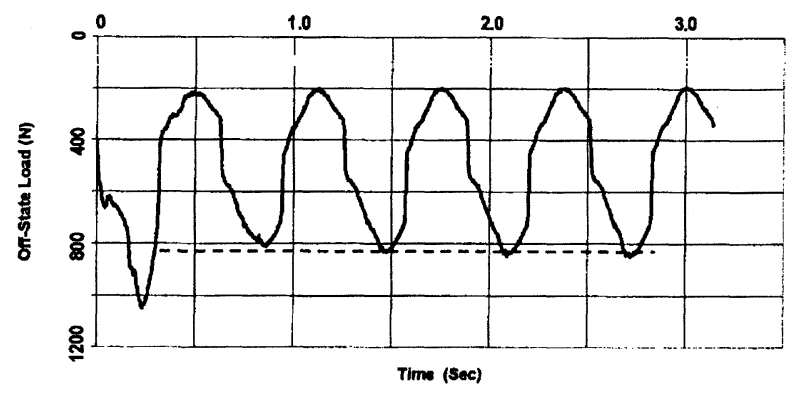

Figure 2 MR damper force during cycling immediately after one year of simulated settling

Shown in Figure 3 is the improvement in fluid durability over several years of formulation research.

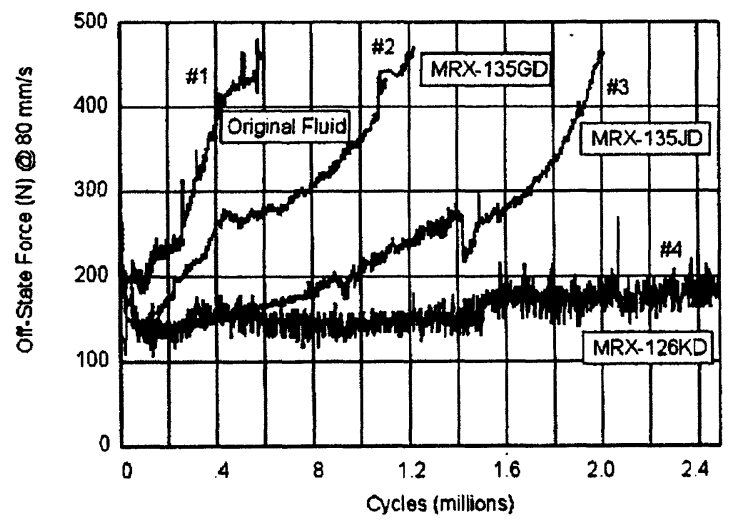

Figure 3 Historical durability test data in Lord Corporation MR fluids

The failure mechanism of an MR fluid is usually an increase in the off-state viscosity due to wear or breakdown of the iron particles, leading to lack of control range. Lord's patented additives prevent wear and breakdown while maintaining the magnetic performance of the fluid. Today MR fluids will last the equivalent of hundreds of thousands of miles in an automotive shock application.

The ultimate test of any material is in actual use. In addition to accelerated and track testing. Delphi has recently tested shocks that have been in actual use for over two years. Shocks from vehicles from Texas and Michigan, with between 50,000 and 72,000 miles, were subjected to performance tests and further accelerated durability testing equivalent to the projected full life of the shocks $(100,000$ miles), to verify the long-term behavior of both the Lord MR fluid and MagneRide dampers.

All shocks tested, from both northern and southern climates, performed within original, as-made, specifications in laboratory testing. The on-state damping force changes were nominal, varying only $3-5 \%$, even after an additional 50,000 miles of laboratory durability were added to the actual mileage on the shocks. See Figure 4.

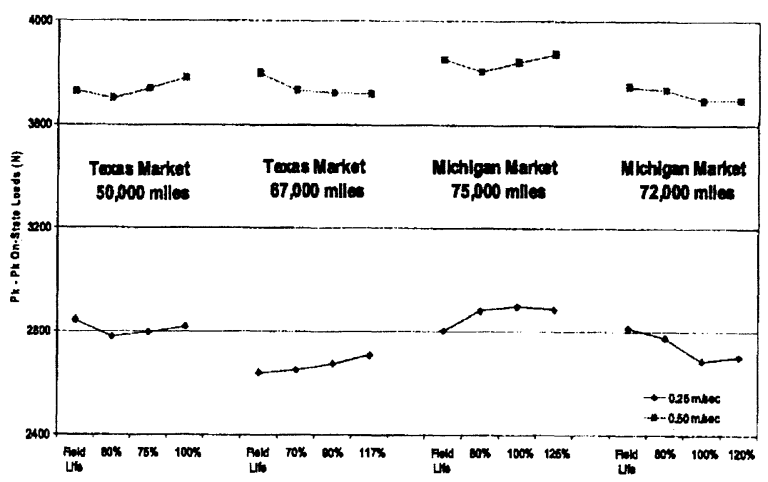

Figure 4 On-state shock performance from field life to $100,000+$ miles $(100 \%=$ projected life $=100,000$ miles $)$

Similarly off-state forces and seal friction with and without side load showed only nominal change from the as-made specification to the field life plus additional 50,000 laboratory durability miles.

It is reasonable to conclude, after three years in the marketplace and many decades of accelerated testing by Lord and Delphi, the durability and stability of MR fluid and shocks are well proven. [7]

\section{VEHICULAR STEER-BY-WIRE}

Automotive design engineers are looking at a host of other potential applications for MR fluid technology, especially in the area of driver feedback, or "feel," that is often not optimized in electric, by-wire systems.

The trend in vehicle industries toward control-by-wire (steer-by-wire, shift-by-wire, throttle-by-wire, brake-by- 
wire, etc.) has created a need for highly controllable, rugged, cost-effective devices to provide realistic forcefeedback sensations to the operator, whether the manual device is a wheel, a joystick, a pedal, or a lever. Commercialized products for forklift vehicles use the Lord sMaRt Steering Brake ${ }^{\mathrm{TM}}$ to sense steering wheel position, control over-steer when the vehicle is moving quickly, and simulate the end-stop limit of driving wheel turn.

With MR fluid inside the Lord sMaRt Steering Brake, the rotor turns freely inside the housing in the absence of a magnetic field. But when the coil is energized, the magnetic field generated causes the iron particles in the MR material to form a chain, creating a resistive torque that is proportional to the current flow in the coil and reacts quickly to changes in the strength of the magnetic field.

The benefits in of MR technology in by-wire applications include:

- Continuously variable, speed-independent torque

- Quick response time (10 milliseconds)

- Smooth, realistic force feedback with high fidelity feel

- Real-time control

- High torque density - 10 times greater than DC motors

- Compact size

- No active forces generated

- Inherent system stability

- Low power consumption (typically $12 \mathrm{~V}, 1 \mathrm{Amp}$ max current)

- Compatible with vehicle electrical systems

United Kingdom-based lift truck manufacturer Linde has taken the technology of programmable feel the furthest in vehicular applications. Linde was the first (in 2000) to incorporate an advanced, fully integrated system developed by Lord, which provides high-fidelity tactile feel in Linde's all-electric active reach trucks with steer-by-wire control.

Linde incorporated the Lord sMaRt Steering Brake to improve operator control and safety, because the company realized during development that the vehicle was unsafe to operate without high-quality tactile feedback to the steering wheel. Linde considered using electric motors but rejected the idea due to high cost, size, weight, and energy usage. Linde eventually chose a Lord MR device because it produced a high-fidelity sense of "feel" to the operator with much lower cost, size, weight, and energy usage than electric motors. The Lord sMaRt Steering Brake is 60 percent smaller than comparable devices and produces the same amount of torque at fraction of the cost and power.

\section{MR STATUS TODAY}

Today, thousands of vehicles are in operation and more than 100,000 MR dampers, shock absorbers and brakes are in use. For automotive platform applications alone, anticipated annual growth in demand for MR devices is more than 1 million.

Production of fluid volume in 2004 reached several hundred tons. The cost of MR fluid ranges from about $\$ 600$ per liter for small quantities to about $\$ 60$ to $\$ 180$ per liter for large volume applications.

Lord Corporation's experience in the development of MR fluids, devices and systems has produced key insights, backed by solid data, into this remarkable technology. Over the past three years, Lord has offered MR Technology Workshops to train others in MR device and system design. Lord offers MR fluid and technology that is:

- Tailored for specific applications

- High strength

- Durable

- Robust

- Highly developed with fundamental material data and device design and models

- Extensive experience-based guidelines

\section{REFERENCES}

1. J.D. Carlson, J.L. Sproston, Proceedings of Actuator 2000, 7th Int. Conf. on New Actuators, 19-21 June, Bremen, Germany, 126-130 (2000).

2. J.D. Carlson, Proceedings of the 3rd World Conference on Structural Control, Vol. 1, 7-11 April, Como, Italy, F Casciati, Ed., Chichester: John Wiley 227-236 (2003).

3. Lord Corporation, Rheonetic Magnetic Fluid Systems, Publication No. PB8003, 1-10 (1996)

4. S.J. McManus, K.A. St. Clair, SAE Technical Paper Series, No. 2000-01-3408, Truck and Bus Meeting and Exposition (2000).

5. Delphi Energy \& Chassis Systems, 2002, Pub. DE-00-E-019 02/02, http://www.delphi.com/pdf/vpr/Magnaride.pdf(2002).

6. General Motors Corp., (2002).

7. L.C. Yanyo, "Magnetorheological (MR) Fluid for Automotive Damping Systems Proceedings", IIR Suspension and Damping Conference, Germany (2004). 